\title{
Bioenergia e resíduos na cadeia de suínos: uma análise de custos e investimentos para transporte de dejetos suínos com posterior geração de bioenergia no município de Toledo/ PR
}

Bioenergy and waste in the chain of pigs: an analysis of costs and investments for the transportation of pig manure with subsequent generation of bioenergy in the city of Toledo / PR

Sandra Mara Pereira ${ }^{1}$

Debora da Silva Lobo Homero Fernandes Oliveira Weimar Freire da Rocha Júnior

\footnotetext{
${ }^{1}$ Sandra Mara Pereira: Mestre em Desenvolvimento Regional e Agronegócio da Unioeste - campus Toledo. Bolsista demanda social pela CAPES. Tem atuado na área de Economia, com ênfase em transporte urbano, fretes, logística, agronegócio brasileiro, nova economia institucional.
}

Debora da Silva Lobo: Graduada pela Universidade Federal do Rio de JaneiroUFRJ em Bacharelado (1990) e Licenciatura (1992) em Matemática, fez mestrado (1998) e doutorado (2003) em Engenharia de Produção pela Universidade Federal de Santa Catarina - UFSC. Atualmente é professora adjunto da Universidade Estadual do Oeste do Paraná- UNIOESTE. Professora Adjunta da Universidade Estadual do Oeste do Paraná - UnioesteTranslog - Grupo de Pesquisa em Transporte, Logística e Modelagem de Sistemas. E-mail: dslobo@uol.com.br.

Homero Fernandes Oliveira; Possui graduação no Curso de Formação de Oficiais Aviadores pela Academia da Força Aérea (1978), graduação em Tecnologia da Computação pelo Instituto Tecnológico de Aeronáutica (1986), o Master Of Science In Operations Research - Naval Postgraduate School (1991) e doutorado em Engenharia de Produção pela Universidade Federal de Santa Catarina na área de Transporte e Logística. Atualmente é professor adjunto da Universidade Estadual do Oeste do Paraná - Campus de Toledo. Professor Adjunto da Universidade Estadual do Oeste do Paraná - Unioeste. Translog - Grupo de Pesquisa em Transporte, Logística e Modelagem de Sistemas. E-mail:homero2@uol.com.br.

Weimar Freire da rocha Jr.: Engenheiro Agrônomo formado pela Universidade Federal de Lavras (1989), Mestre em Economia Agrária (Economia Aplicada) pela Universidade de São Paulo (1994) e Doutor em Engenharia de Produção pela Universidade Federal de Santa Catarina (2001). Atualmente é professor associado da Universidade Estadual do Oeste do Paraná onde leciona no Curso de Ciências Econômicas e no Programa de Mestrado em Desenvovimento Regional \& Agronegócio. Pesquisador produtividade do CNPq.Professor Associado da Universidade Estadual do Oeste do Paraná - Unioeste Translog - Grupo de Pesquisa em Transporte, Logística e Modelagem de Sistemas. Email:wrochajr2000@gmail.com. 


\section{Resumo}

O trabalho aborda o tema "análise de custos e de investimentos, para a coleta de dejetos suínos (fase de terminação), em propriedades rurais do município de Toledo, tendo como destino final um centro de bioenergia". No referencial teórico abordam-se tópicos como caracterização da suinocultura, modelo e custos de transporte, e análise de investimentos. Na metodologia, coletou-se informações relacionadas à 380 propriedades com suínos em fase de terminação, realizando a roteirização com auxílio da heurística de Clark \& Wright. Foram pesquisadas informações referentes aos veículos e equipamentos utilizados nesta atividade, os custos operacionais e de investimento para a aquisição dos mesmos, assim como para a implantação de um centro de biodigestão. Analisaram-se os potenciais de geração de dejetos, biogás e energia elétrica com as quantidades de suínos existentes nas propriedades pesquisadas. Para a implementação do projeto, serão necessários grandes investimentos, contudo, a rentabilidade com a venda de biogás e energia elétrica compensará. Conclui-se que é viável a implementação de semelhante projeto, por beneficiar os produtores rurais, que terão nova fonte de renda com a venda dos dejetos; possibilitar uma nova matriz energética, utilizando um resíduo altamente poluidor e, preservar o meio ambiente, que não sofrerá os danos pelo despejo dos dejetos.

Palavras-Chave: Custos de transporte. Dejetos suínos. Bioenergia

\section{Abstract}

The work addresses the theme "analysis of costs and investments for the collection of pig manure (in the finishing phase) in rural properties in the city of Toledo, with the final destination a center of bioenergy". The theoretical base includes topics, transportation costs and models, and investment analysis; characterization of swine production. In the methodology, collected information is related to properties with 380 pigs in the finishing stage, performing with the aid of heuristic routing of Clark \& Wright. Were researched information on vehicles and equipment used in this activity, operating costs and investment for the acquisition of them, as well as for the establishment of a center of biodigestion. We analyzed the potential to generate waste, biogas and electricity and the quantities of pigs in the properties searched. For the implementation of the project will require major investments, however, profitability with the sale of biogas and electricity compensate. It follows that it is feasible to implement a similar project, for the benefit of farmers, who will have new source of revenue with the sale of pig slurry, providing a new energy matrix, using a highly waste polluter, and preserve the environment, not suffer the dump indiscriminate of pig manure.

Key-words: Transportation costs. Pig manure. Bioenergy 


\section{INTRODUÇÃO}

Vem se delineando nas últimas décadas nos Estados do Paraná, e Santa Catarina, uma mudança no paradigma energético, uma vez que com a crescente evolução do sistema agroindustrial da suinocultura, surgem problemas ambientais que impactam fortemente nas regiões onde estão concentrados os locais de produção de suínos, decorrente do grande volume de dejetos dessa atividade. O biogás é um subproduto desta atividade com um alto potencial poluidor, mas que, quando adequadamente manipulado, pode ser fonte de energia para as mais variadas aplicações, além de poder ser comercializado no mercado de carbono.

Com o uso adequado do biogás como fonte energética alternativa, é possível transformar um resíduo altamente deletério para o meio ambiente em uma fonte de energia com geração de renda. Mas para se produzir este gás combustível é necessário manipular o dejeto suíno, levando-o a um local adequado e fazendo os devidos tratamentos com as mais variadas técnicas de produção de biogás.

Partindo da premissa que o dejeto será transportado para um centro de produção de biogás, este estudo tem o objetivo de analisar o custo de transporte do dejeto de suíno das propriedades rurais até um centro de bioenergia para produção de biogás e suas perspectivas e desafios.

De mais a mais, esta atividade agroindustrial tem a característica de ser viável socialmente por envolver elevado contingente de produtores rurais, principalmente no segmento denominado de agricultura familiar que, além de contribuir na redução do êxodo rural e absorver mão-de-obra na propriedade, possibilita a geração de renda e fixa o homem no campo. Sob o ponto de vista ambiental ela pode reduzir impacto dos dejetos ao meio ambiente pela transformação de um resíduo com alta carga poluente em um produto com valor agregado e fonte de energia com múltiplo uso que tem o biogás podendo inclusive ser comercializado no mercado de crédito de carbono.

O estudo está assim segmentado, a primeira parte consta da introdução em que é apresentado uma visão panorâmica do estudo e o objetivo, na segunda seção é feita uma breve revisão de literatura da suinocultura, dos modelos de transporte, e seus custos, além da análise de investimento. Na seção seguinte é elaborado o procedimento metodológico. A quarta seção são apresentados os resultados e discussões para posterior conclusão.

\section{Caracterização da Suinocultura}

Segundo dados apresentados pela ABIPECS (2009), o Brasil ocupava em 2004 a $4^{\text {a }}$ (quarta) colocação em termos de produção mundial de carne suína. Ademais, conforme apresentado no Relatório ABIPECS 2008, a produção brasileira teve um crescimento de aproximadamente $16 \%$ 
no período de 2004 a 2008, sendo que neste último atingiu mais de 3 milhões de toneladas.

Com relação à produção nacional, a Tabela 1 denota a quantidade de carne suína produzida no período de 2004 a 2008, com estimativa para o ano de 2009.

Tabela 1 - Produção brasileira de carne suína de 2004 a 2009 (mil toneladas)

\begin{tabular}{l|llllll|l|l}
\hline ESTADOS/ANO & 2004 & 2005 & 2006 & 2007 & 2008 & $\begin{array}{l}2009 \\
(1)\end{array}$ & VAR (2) \\
\hline \multicolumn{1}{l}{ PRODUÇÃO INDUSTRIAL } & & & & & & \\
SC & 586,9 & 619,0 & 732,6 & 754,3 & 724,3 & 751,7 & 3,78 \\
RS & 383,3 & 416,7 & 465,6 & 481,4 & 528,4 & 585,9 & 10,88 \\
$\underline{P R}$ & $\underline{376,1}$ & $\underline{389,6}$ & $\underline{430,8}$ & $\underline{437,2}$ & $\underline{444,3}$ & $\underline{487,9}$ & $\underline{9,80}$ \\
MG & 213,1 & 251,8 & 314,9 & 335,5 & 348,1 & 375,0 & 7,73 \\
SP & 171,2 & 168,1 & 170,0 & 176,6 & 147,0 & 147,4 & 0,32 \\
MT & 79,1 & 104,7 & 111,5 & 116,2 & 140,0 & 152,3 & 8,79 \\
GO & 97,2 & 108,7 & 115,1 & 121,1 & 127,0 & 137,6 & 8,39 \\
MS & 67,4 & 71,7 & 68,5 & 70,2 & 70,9 & 80,5 & 13,56 \\
SUB TOTAL & $1.974,3$ & $2.130,4$ & $2.408,8$ & $2.492,4$ & $2.529,9$ & $2.718,3$ & 7,45 \\
OUTROS & 159,1 & 116,7 & 122,0 & 151,1 & 154,1 & 154,4 & 0,18 \\
ESTADOS & $2.133,4$ & $2.247,0$ & $2.530,9$ & $2.643,6$ & $2.684,0$ & $2.872,7$ & 7,03 \\
TOTAL & 487,9 & 462,2 & 412,3 & 354,0 & 342,4 & 317,8 & $-7,18$ \\
INDUSTRIAL & $2.621,3$ & $2.709,3$ & $2.943,1$ & $2.997,6$ & $3.026,4$ & $3.190,4$ & 5,42 \\
\hline SUBSISTÊNCIA & BRASIL & &
\end{tabular}

FONTE: Adaptado de ABIPECS (2010).

(1) Estimativa.

(2) Variação percentual da produção do ano de 2008 para 2009.

Pode-se perceber que dentre os estados com maior produção de suínos em caráter industrial, o Paraná ocupa a $3^{\text {an }}$ (terceira) posição, estando atrás apenas dos estados de Santa Catarina e Rio Grande do Sul. A produção paranaense atingiu 444,3 mil toneladas de carne em 2008, cerca de $3 \%$, apenas, menor que a produção gaúcha (segunda colocada no ranking nacional). (ABIPECS, 2010).

Conforme dados do IPARDES (2010), o efetivo rebanho de suínos no Paraná cresceu consideravelmente no ano de 2007, comparando-se ao período de 2004 a 2006 e atingiu mais de 4,6 milhões de animais em 2008, sendo que destes, aproximadamente 1,75 milhões, está situado na região oeste do estado, o que destaca sua importância, não somente em termos de produção estadual, mas nacionalmente.

A Tabela 2 demonstra o efetivo rebanho de suínos paranaense no período de 2004 a 2007, distribuído por regiões do estado. 
Tabela 2 - Efetivo rebanho de suínos do estado do Paraná

\begin{tabular}{llllll}
\hline REGIÃO/ANO & 2004 & 2005 & 2006 & 2007 \\
\hline Centro-Ocidental & 147.789 & 138.285 & 126.652 & 128.717 \\
Norte Central & 389.733 & 393.567 & 401.979 & 382.041 \\
Norte Pioneiro & 179.192 & 176.195 & 177.811 & 145.572 \\
Centro-Oriental & 562.689 & 571.954 & 569.126 & 593.306 \\
Oeste & $\underline{1.405 .120}$ & $\underline{1.439 .357}$ & $\underline{1.465 .704}$ & $\underline{1.761 .046}$ \\
Sudoeste & 745.250 & 758.227 & 711.612 & 699.207 \\
Centro-Sul & 391.310 & 375.158 & 355.755 & 366.480 \\
Sudeste & 397.263 & 356.530 & 340.594 & 344.587 \\
Metropolitana & de & 242.516 & 207.407 & 215.195 & 205.610 \\
Curitiba & 127.191 & 131.215 & 121.607 & 109.390 \\
Noroeste & 4.588 .053 & 4.547 .895 & 4.486 .035 & 4.735 .956 \\
\hline TOTAL & &
\end{tabular}

FONTE: Adaptado de IPARDES (2010).

Importante destacar, na Tabela 2, a região Oeste em relação ao estado do Paraná, no que tange o efetivo rebanho de suínos. Além de ser detentora do maior efetivo em todo o período apresentado, ainda ostentou um crescimento de pouco mais de $20 \%$ no ano de 2007 , enquanto as demais regiões tiveram significativa queda ou baixo percentual de aumento para o mesmo período.

A Figura 1 denota, com maior clareza, a representatividade de cada região na produção total do estado, tomando por base o ano de 2008.

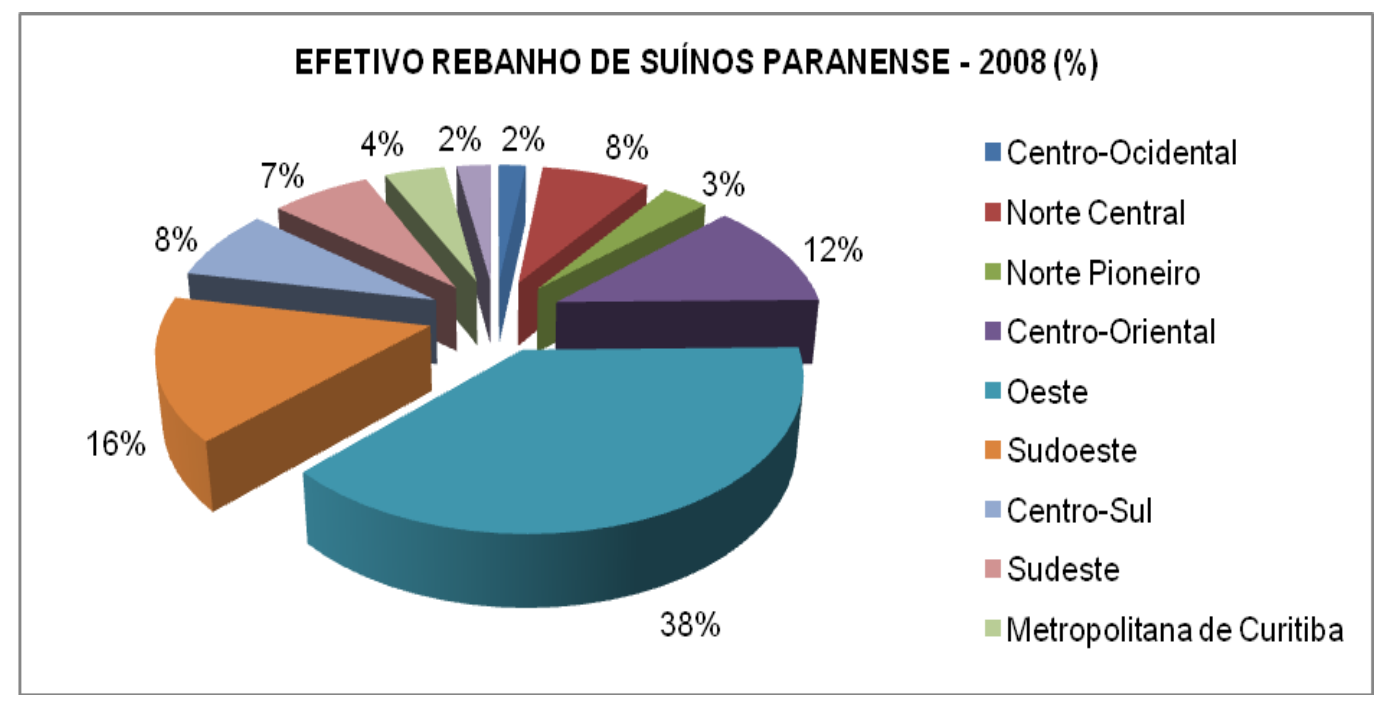

Figura 1 - Efetivo rebanho de suínos paranaense em 2008 FONTE: IPARDES (2010). 
O grau de importância da região Oeste do estado do Paraná é facilmente percebido quando se analisa o efetivo rebanho de suínos distribuído por municípios. Conforme pode ser observado na Tabela 3, dentre os dez municípios com maior número de animais no estado, quatro estão situados na região oeste e representam juntos, aproximadamente, $16 \%$ do total estadual. (IPARDES, 2010).

Tabela 3 - Participação dos dez municípios com maior rebanho de suínos no estado do Paraná (2008)

\begin{tabular}{l|l|l}
\hline MUNICÍPIO & REBANHO & PARTICIPAÇÃO (\%) \\
\hline$\underline{\text { Toledo }}$ & $\underline{410.943}$ & $\underline{8,87}$ \\
$\underline{\text { Marechal Cândido Rondon }}$ & $\underline{\underline{156.205}}$ & $\underline{3,37}$ \\
Castro & 135.566 & 2,93 \\
Nova Santa Rosa & $\underline{114.962}$ & $\underline{2,48}$ \\
Arapoti & 102.363 & 2,21 \\
Piraí do Sul & 100.349 & 2,17 \\
Guaraniaçu & $\underline{81.560}$ & $\underline{1,76}$ \\
Enéas Marques & 77.274 & 1,67 \\
Dois Vizinhos & 64.036 & 1,38 \\
Francisco Beltrão & 62.065 & 1,34 \\
TOTAL & 1.305 .323 & 28,18 \\
PARANÁ & 4.631 .600 & 100 \\
\hline
\end{tabular}

FONTE: IPARDES (2010).

A suinocultura pelo processo de fermentação dos dejetos produz gases de efeito estufa (GEEs) como metano, $\mathrm{CO}_{2}$ e sulfúrico. Estes gases, quando não há nenhum tipo de tratamento, são liberados diretamente para a atmosfera por meio do sistema de manejo de lagoas.

A próxima seção irá abordar os modelos de transporte que para apresentar as alternativas de deslocamento dos dejetos de suíno até o local que tratamento e transformação do biogás.

\section{Modelos de Transporte}

Os problemas de roteirização podem ocorrer de duas formas: com ou sem restrições. Denominam-se como sendo "sem restrições" os casos em que o tempo e a capacidade já foram pré-determinados, ou seja, não participam no problema da roteirização, bastando apenas efetuar o melhor roteiro de coleta/entrega de produtos. Este problema, na literatura técnica, recebe a definição de Problema do Caixeiro Viajante (PCV), pois o autor que primeiro realizou a análise tomou como exemplo os caixeiros-viajantes, que precisam visitar determinado número de cidades em cada região, minimizando o percurso e, em conseqüência, o custo (NOVAES, 2007). 
De outra forma, o método "com restrições" realiza todas as interações necessárias: combina quantidades, localidades (bolsões ou zonas) e distâncias, na intenção de encontrar a melhor solução possível, consideradas as restrições impostas ao problema. Podem-se encontrar diversos métodos na literatura e neste item serão citadas as bases de quatro modelos: varredura, k-opt, out of kilter (HOK), e Clark e Wright.

O método de varredura é considerado simples e de rápida computação, contudo apresenta precisão de $10 \%$, o que pode ser bom apenas num curto período de tempo. A análise dos resultados deve ser realizada de forma minuciosa, para não haver distorções nos resultados (NOVAES, 2007).

De acordo com Novaes (2007), os passos do método de varredura são os seguintes (ver Figura 2):

1. Tomar o depósito como centro e definir um eixo passando pelo mesmo, que geralmente coincide com a linha horizontal.

2. Girar o eixo em torno do depósito, em sentido horário, até que a linha passe por um cliente e, desta forma, o inclua.

3. Testar se o cliente pode ser incluído no roteiro em formação em função de (a) o tempo para atendimento do cliente excede a jornada de trabalho do dia?; (b) a quantidade de mercadoria a ser entregue no cliente excede a capacidade de carga do veículo? Se estas restrições não forem violadas, o cliente pode ser inserido no roteiro e passa-se para os próximos passos. Caso as restrições sejam quebradas, começa-se novamente o processo.

4. Caso o novo cliente não possa ser inserido no roteiro em formação (devido às restrições), este roteiro deve ser fechado e inicia-se outro roteiro. O procedimento acaba quando todos os clientes tiverem sido incluídos em um roteiro.

5. Para cada roteiro, deve-se aplicar um método de melhoria, para minimizar os percursos.

Segundo Teixeira e Cunha (2008), o método de varredura (Figura 2), proposto inicialmente por Wren e Holiday (1972), mesmo fornecendo resultados melhores que o da heurística de economias para algumas categorias de problemas de roteirização, não é muito consistente por apresentar desempenho deficiente na presença de restrições de janelas de tempo apertadas, prejudicando a lógica intrínseca de agrupamento de clientes baseada exclusivamente na proximidade geográfica (ou geométrica) dos pontos visitados. 


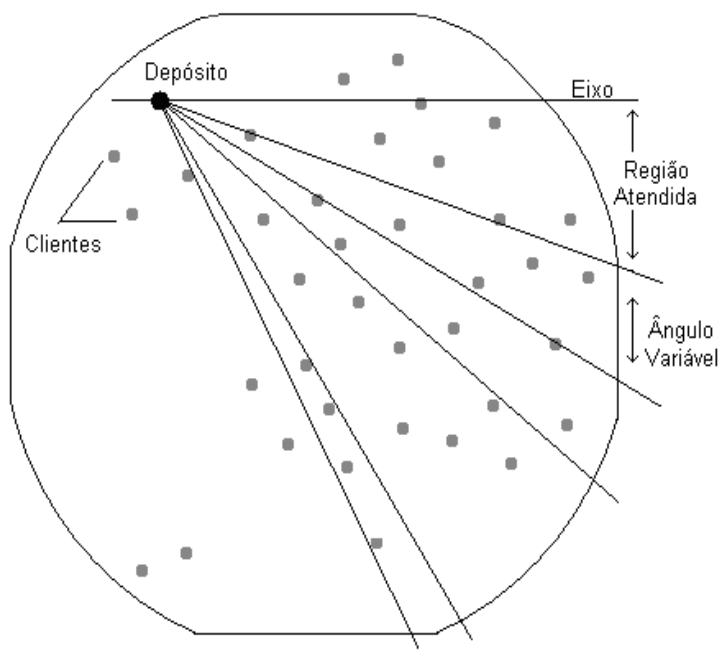

(a)

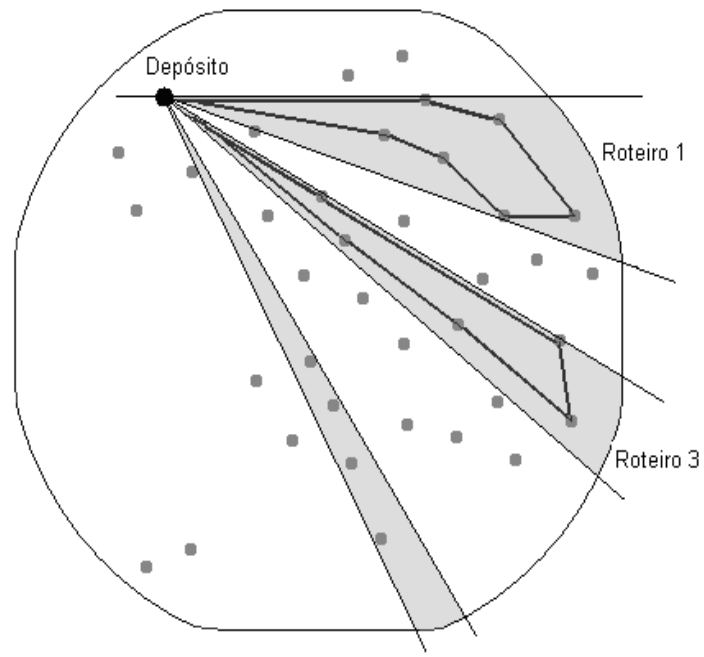

(b)

Figura 2 - Evolução do Método de Varredura

Fonte: Adaptado de Novaes (2007)

Quanto à heurística do tipo k-opt, proposto por Lin e Kernighan em 1973 , no qual $k$ arcos são removidos de um roteiro e substituídos por outros $k$ arcos, com a finalidade de diminuir a distância total percorrida. Quanto maior o valor de $k$, melhor a precisão do método, contudo maior é o esforço computacional. Na prática, são considerados os métodos 2-opt e 3-opt, isto é, $k$ assumindo os valores 2 ou 3 , conforme Figuras 3 e 4 (CUNHA; BONASSER; ABRAHÃO, 2002).

Resumidamente, o método 2-opt realiza trocas entre pares de arcos possíveis, refazendo as conexões quando ocorre melhoria no roteiro; encerrando o processo quando não houver mais trocas que resultem em melhorias.

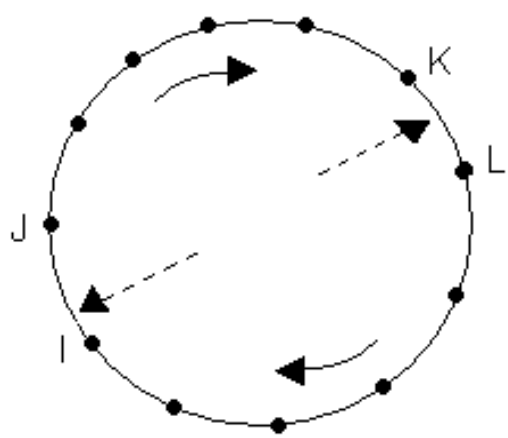

(a) Roteiro Básico

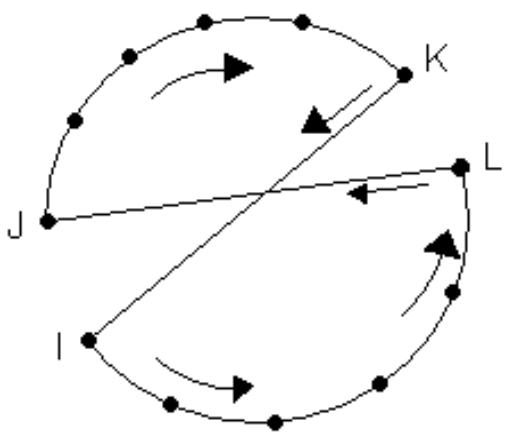

(b) Roteiro Modificado

Figura 3 - Movimento 2-opt

Fonte: CUNHA; BONASSER; ABRAHÃO (2002) 
Segundo Cunha; Bonasser; Abrahão (2002), este procedimento (2opt) possui ordem de complexidade $O\left(n^{2}\right)$. Como pode ocorrer inversão de sentido em parte do roteiro, conforme mostrado na Figura 10, pressupõe-se simetria de distâncias.

No 3-opt, são considerados três arcos (ao invés de dois), para se avaliarem as alterações nas conexões entre os nós, o que resulta em sete possíveis combinações, conforme visto na Figura 4. Destas, apenas quatro combinações $(4,5,6$ e 7$)$ representam trocas entre três arcos; as combinações 1, 2 e 3 correspondem a trocas do tipo 2-opt.

(1)

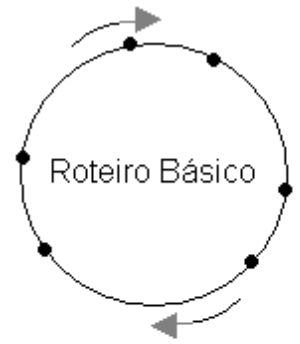

(4)

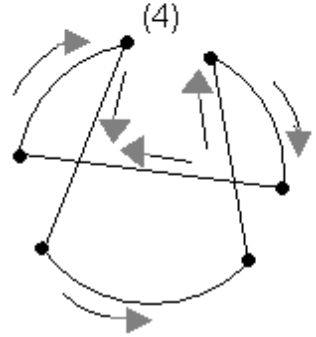

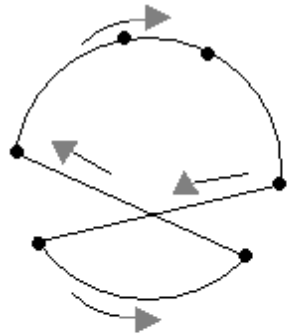

(5)

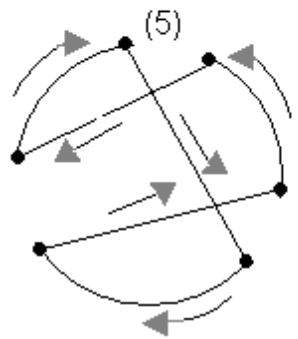

(2)

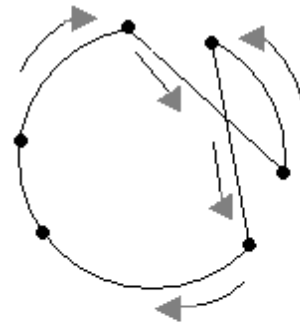

(6)

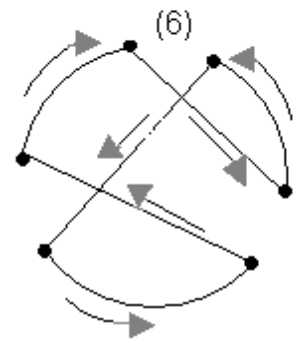

(3)

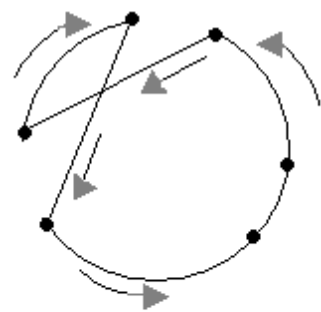

(7)

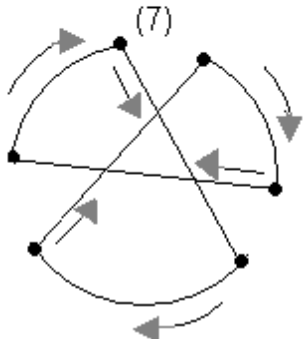

Figura 4 - Movimentos possíveis para o 3-opt (combinação de nós) Fonte: CUNHA; BONASSER; ABRAHÃO (2002)

Os métodos de melhorias 2-opt e 3-opt partem de um roteiro inicial, obtido através de algum outro método, como o de varredura, por exemplo. Na maioria das vezes utiliza-se um procedimento simples, que permita gerar rapidamente um roteiro, que depois seja melhorado através dos procedimentos 2-opt e 3-opt (CUNHA; BONASSER; ABRAHÃO, 2002).

A heurística out-of-kilter (HOK), baseada no trabalho de Desrochers e de Verhoog (de 1991), consiste em uma generalização do método de economias proposto por Clark e por Wright (de 1964), considerando a frota heterogênea, de forma a evitar que as sucessivas combinações de pontos para formar roteiros levem à união de pontos e à criação de roteiros que não aproveitem plenamente a capacidade dos veículos (TEIXEIRA; CUNHA, 2008).

Deste modo, não se unem os pontos seguindo uma ordem decrescente de economias, mas consideram-se todas as possibilidades de combinação dos pontos extremos dos roteiros parciais, resolvendo um 
problema de designação em grafo bipartido. A intenção é encontrar a solução que maximize a economia total, que é resultante da soma das economias das rotas parciais, e cada rota poderá ser combinada com apenas uma outra rota. Conseqüentemente, sucessivos problemas de designação devem ser resolvidos até que não haja mais possibilidade de união de rotas, por restrições de viabilidade ou por não haver mais economias (TEIXEIRA; CUNHA, 2008).

Uma técnica que tem sido empregada, por permitir a inclusão de diversas restrições, é a heurística de Clark e Wright, formulada em 1963, geralmente utilizada na solução de problemas isolados (empresa ou cliente específicos), muito utilizada em softwares de roteirização (NOVAES, 2007).

A heurística de Clark e Wright tem como objetivo gerar roteiros que respeitam as restrições de tempo e de capacidade, mas visando à minimização da distância total percorrida pela frota, e, à medida que o modelo vai gerando roteiros eficientes, a frota é otimizada (por vezes reduzida), incidindo na redução de custos de capital e de operacionalização.

Esta heurística, segundo Martins et alii (2004), fundamenta-se na noção de economias (definido como o custo da combinação, ou união, de duas sub-rotas existentes). Refere-se a uma heurística iterativa de construção baseada numa função gulosa de inserção.

Novaes (2007) cita que o método Clark e Wright inicia com a análise de todas as combinações possíveis entre os nós (ou pontos), sempre dois a dois, ordenando, na seqüência, as combinações em ordem decrescente dos ganhos. As combinações com maiores ganhos são as que abrangem os pontos mais distantes do depósito ou fábrica (mas próximos entre si), vindo em seguida, na direção do depósito (Figura 5).

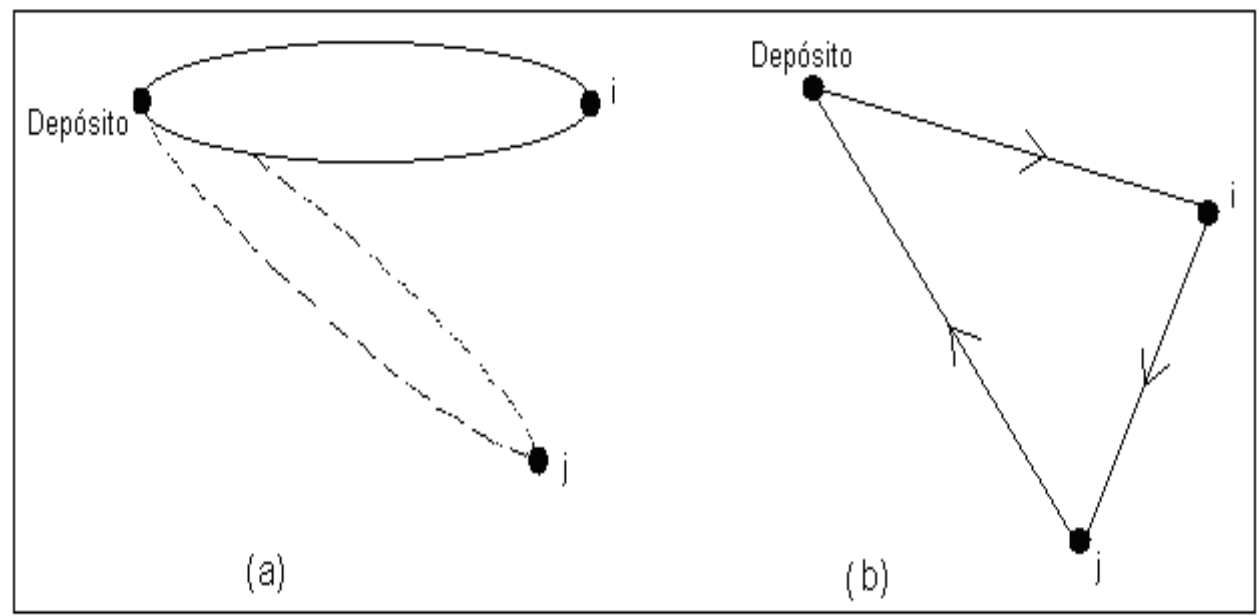

Figura 5 - Exemplo de integração de dois clientes (i e $]$ ) num roteiro compartilhado

Fonte: adaptado de Novaes (2007). 
Observa-se, na Figura 5 esquema (a), que o primeiro roteiro é realizado com $i$ e $j$ independentes, ou seja, o veículo sai do depósito vai ao ponto $i$ e retorna, para depois ir ao ponto $j$. No esquema (b), é realizada a integração dos dois pontos, considerando-se que o ponto $i$ é atendido antes do ponto $j$. Deste modo, a metodologia de Clark e Wright vai realizando as iterações, aproximações, visando à minimização de distâncias e de frota.

de seis etapas:

Segundo Novaes (2007), o método de Clark e de Wright é composto

1. Combinam-se todos os pontos (clientes), dois a dois, e calculase o ganho de cada relação pela fórmula (1).

$$
\mathrm{g}_{i, j}=\mathrm{d}_{\mathrm{D}, i}+\mathrm{d}_{\mathrm{D}, j}-\mathrm{d}_{i, j}
$$

Em que:

$\mathrm{g}_{i, j}=$ ganho da relação

$\mathrm{d}_{\mathrm{D}, i}=$ distância entre o depósito e o cliente $i$

$\mathrm{d}_{\mathrm{D}, j}=$ distância entre o depósito e o cliente $j$

$\mathrm{d}_{i, j}=$ é a distância entre os clientes $i$ e $j$;

2. Organizar as combinações de $i$ e $j$, em ordem decrescente de ganhos.

3. Combinar dois nós (pontos) que tiveram maior ganho, na análise de outras combinações, deslocar para baixo da lista, obedecendo à seqüência decrescente de ganhos.

4. Para uma dupla de pontos ( $i$ e $j$ ), verificar se já fazem parte de algum roteiro iniciado:

- $\quad$ se não foram incluídos em outro roteiro iniciado, criar um novo roteiro;

- $\quad$ se $i$ pertence a outro roteiro, verificar se este ponto é o primeiro ou o último do roteiro; caso positivo, incluir a dupla de pontos ( $i$ e $j$ ) na extremidade apropriada. Realizar semelhante análise com o ponto $j$; caso nenhum dos pontos satisfaça esta condição, passar para o próximo passo;

- $\quad$ se os pontos $i$ e $j$ fazem parte, separadamente, de roteiros iniciados diferentes, verificar se são extremos dos roteiros; caso positivo, incorporar os dois roteiros em um, unindo $i$ e $j$; caso negativo, ir para a etapa 5;

- $\quad$ se $i$ e $j$ pertencerem a um mesmo roteiro, ir para a etapa 5.

5. Quando do acréscimo de mais um ponto (nó) no roteiro, ou da fusão de dois pontos, verificar se a nova configuração cumpre as restrições de tempo e capacidade.

6. Quando todos os pontos (clientes) forem incluídos no roteiro, termina-se o processo.

Observa-se que existem diversas heurísticas possíveis de serem utilizadas para elaboração de roteirização. Há necessidade de conhecer quais as necessidades e restrições existentes, e quais as 
intenções da empresa (minimizar tempo e quantidade de caminhões, por exemplo), para decidir pela melhor metodologia a ser empregada.

\section{Custos de Transportes}

Os serviços de transporte e a consequente roteirização, segundo Ching (2007), precisam atender a quatro questões: (1) o que é transportado?; (2) para onde?; (3) quando?; (4) como? Os custos de transporte devem considerar as características do produto (volume, densidade, valor, formato, etc.) e do mercado (localização, concorrência, sazonalidade, tráfego de cargas, etc.). Portanto, justifica-se uma análise complexa de todos os fatores e variáveis relacionadas à ação do transporte e seus referidos custos.

De acordo com Martins (1998), os custos são basicamente divididos em diretos, que possuem alguma medida de consumo na produção (embalagens utilizadas, quilogramas de material, horas de mão-de-obra, entre outros); e indiretos, que não podem ser mensurados de forma exata, mas estão relacionados à produção (aluguel, salários administrativos, entre outros).

No caso dos transportes, Valente, Passaglia, Novaes (2003), fazem o desdobramento dos custos, da seguinte forma:

- Custos Diretos:

○ $\quad$ Fixos (depreciação, remuneração do capital, salário de motoristas, licenciamento, seguros);

- Variáveis (combustível, óleos lubrificantes, pneus e recapagens, peças e acessórios de oficina, mão-de-obra de manutenção, lavagem);

- Custos Indiretos: ou administrativos, necessários para manter o sistema de transportes da empresa (aluguel e pessoal de armazéns, publicidade, comunicações, impostos e taxas, viagens e estadas, despesas financeiras, construção, conservação e limpeza).

Outros fatores que afetam os custos são: a quilometragem percorrida (o custo por quilômetro reduz quando o veículo roda mais, pois os custos fixos são divididos pela quilometragem); tipo de tráfego (em áreas urbanas, a velocidade é menor e o desgaste do veículo é maior); características das vias (asfaltada, em leito natural, sinuosidade, condições de conservação); região de abrangência (os salários, preços de combustível, impostos, variam nas regiões e/ou Estados); porte do veículo (quanto maior a capacidade do veículo, menor é o custo por quilômetro, contudo deve-se analisar a utilização de veículos maiores em função das outras restrições); fluxos (cargas de retorno, por exemplo, auxiliam na redução do valor do frete) (VALENTE; PASSAGLIA; NOVAES, 2003). 
A apuração correta de todos os custos envolvidos no transporte é de fundamental importância para o bom desempenho das empresas, independente da área de atuação, gerando tanto benefícios imediatos (controle e redução de custos desnecessários), quanto num futuro próximo (renovação a frota, realização de manutenção, previsão de despesas, etc.).

\section{Análise de investimentos}

Ao decidir pela realização de um investimento, devem ser analisados diversos fatores como riscos e incertezas, aceitação do produto ou serviço pelos clientes, quantidade de recursos necessários, período de retorno deste investimento, entre outros.

Segundo Cavalcanti; Plantullo (2008), para uma análise de projetos de investimento ideal, se faz necessário o uso de um conjunto de técnicas (quantitativas, analíticas e estatísticas), bem como a composição de cenários presentes e futuros, além de fatores financeiros que possam interferir nos resultados do projeto.

Casarotto Filho; Kopittke (1996) citam que a decisão da implantação de um projeto deve considerar os critérios econômicos (como a rentabilidade do investimento); critérios financeiros (disponibilidade de recursos) e critérios imponderáveis, como a satisfação ou a aceitação de clientes e fornecedores, que, em um primeiro momento, não podem ser convertidas em dinheiro.

Uma análise econômico-financeira isolada não será útil para a tomada de decisão e sucesso de um investimento. Há necessidade de serem analisados fatores não facilmente quantificáveis e, por vezes, se faz necessária uma certa intuição empreendedora.

Para um diagnóstico rápido e simplificado dos investimentos, podem-se utilizar índices de balanço. "Índice é a relação de contas ou grupo de contas das demonstrações financeiras, que visa evidenciar determinado aspecto da situação econômica ou financeira de uma empresa" (MATARAZZO, 2008, p. 147). Alguns dos índices mais utilizados são: rentabilidade, liquidez, participação de capitais de terceiros, endividamento, entre outros. Estes índices servem como parâmetro de avaliação da empresa, tanto pelos administradores quanto pelos interessados em investimento (bancos, acionistas, fornecedores, entre outros).

Não há uma quantidade ou uma delimitação exata de quais e quantos índices utilizarem, sendo que a decisão depende apenas das informações disponíveis e da profundidade com que se deseja conhecer a empresa.

\section{PROCEDIMENTO METODOLÓGICO}

A pesquisa foi desenvolvida no ano de 2008, com consultas aos sítios do IBGE e da prefeitura do município de Toledo-PR. Para o levantamento das informações das propriedades, realizaram-se visitas ao 
escritório do Instituto Ambiental do Paraná (IAP), órgão regulador ambiental do Estado, em Toledo, onde foram analisados arquivos e documentos disponíveis das propriedades com licença ambiental de operação na suinocultura.

Ao todo, foram coletados dados de 380 propriedades com criação de suínos em fase de terminação, observadas as características: posicionamento geográfico (latitude e longitude); quantidade de suínos; forma de armazenamento dos dejetos suínos (e/ou tratamento); destinação destes dejetos; origem da água da propriedade e; proximidade de rio ou nascente.

No estudo foi empregado o modelo de caminhão normalmente utilizado na região para este tipo de serviço, sendo o veículo com capacidade de carga total de 13 toneladas. A escolha deste veículo, com um eixo na carroceria (tipo toco), justifica-se por apresentar melhor desempenho nas estradas rurais da região (na sua maioria em leito natural), conseguindo facilidade de acesso e de manobra nas propriedades. Possui também bom desempenho e rendimento no trânsito em estradas secundárias, além de custo-benefício apropriado, se comparado à caminhões semelhantes.

O equipamento a ser instalado na carroceria do caminhão é composto de um reservatório metálico (chapa de aço carbono de 4,75 mm de espessura), com quebra-ondas internos para reduzir a sobrecarga ou a movimentação inercial brusca do conteúdo. As dimensões são adaptadas a cada veículo em função da capacidade de carga, da distância entre eixos, da finalidade e da necessidade do cliente. Possui também uma bomba, com potência de $25 \mathrm{HP}$, fabricada em ferro fundido, com capacidade de sucção de 1.000 litros de dejetos por minuto, e com vazão de saída de 300 litros por minuto.

Para que fosse realizada a análise correta dos custos de transporte, foi necessário gerar roteiros, que atendessem à todas as 380 propriedades, para a coleta de dejetos. Optou-se por utilizar a heurística de Clark \& Wright para a realização da roteirização, por apresentar um erro médio de $2 \%$ (relativamente baixo), e por ser utilizado em diversos softwares de roteirização. Esta heurística, tem como objetivo, gerar roteiros que respeitam as restrições de tempo e de capacidade, mas visando a minimização da distância total percorrida pela frota, e, à medida que o modelo vai gerando roteiros eficientes, a frota é otimizada (por vezes reduzida), incidindo na redução de custos de capital e de operacionalização.

$A$ atividade inicia quando o veículo, munido do equipamento necessário, vai à propriedade rural, coleta o dejeto suíno, indo para outra propriedade e executando o mesmo processo até ter sua carga máxima atingida, dirigindo-se então até o centro gerador de bioenergia, para realizar a respectiva descarga.

Para o cálculo custos de transporte, utilizou-se a análise de Custos Operacionais citada por Valente; Passaglia; Novaes (2003). Este modelo, baseado no método de custos médios desagregados, possibilita a verificação de cada componente sob o aspecto monetário. Diversas 
empresas transportadoras utilizam este modelo de custos, por ser de fácil levantamento e elaboração.

Tal análise englobou todas as despesas relacionadas ao veículo, ao equipamento utilizado, à manutenção, despesas com pessoal e encargos sociais, impostos, combustível, enfim, tudo que esteja relacionado ao funcionamento do veiculo para coleta de dejetos. Para a coleta dos custos dos veículos e do equipamento, foram contatadas empresas revendedoras, via telefone, internet ou pessoalmente.

As informações para a análise são divididas em quatro grandes grupos: dados gerais; dados de preços, dados de operação do veículo e, dados de operação e transporte, para maiores detalhes veja PEREIRA, 2009. Com a combinação dessas informações foi possível saber a quantidade de veículos necessária para a coleta diária de dejetos nas 380 propriedades. Então realizou-se a análise de investimentos, a qual utilizou cinco índices de rentabilidade, quais sejam:

- Taxa mínima de atratividade (TMA): o projeto deve ser atrativo, rendendo no mínimo, a taxa de juros equivalente a rentabilidade das aplicações corrente de baixo risco. No Brasil, utiliza-se como base a rentabilidade da caderneta de poupança, que atualmente é de $8 \%$ ao ano. Ou seja, qualquer investimento que proporcione uma rentabilidade igual ou superior a $8 \%$ a.a. será viável;

- Valor presente líquido (VPL): reflete a riqueza, em valores monetários, do investimento, medida pela diferença entre o valor presente das entradas e saídas de caixa, a uma determinada taxa de desconto. É considerado atraente todo investimento maior ou igual a zero;

- Taxa interna de retorno (TIR): é considerado rentável o investimento que apresentar TIR > TMA. Ela iguala o VPL a zero, e é uma das formas mais complexas de analisar as propostas de investimento de capital. Foi utilizada a função do programa Excel para este cálculo;

- Taxa de rentabilidade (TR): não é uma medida de rentabilidade de capital mas da capacidade da empresa gerar lucro e poder capitalizar-se. A análise é de quanto a empresa obtém de lucro para cada $\$ 100$ investidos, quanto maior melhor a rentabilidade;

- Tempo de retorno do investimento (Payback): em quanto tempo (meses ou anos) o dinheiro investido retornará. É realizado analisando-se o fluxo de caixa, e quando os investimentos (saldos negativos) anularem-se com as entradas de caixa (receitas), ter-seá o período de payback.

\section{RESULTADOS E DISCUSSÕES}

Após a coleta e análise das informações referentes às 380 propriedades rurais, que possuem terminação de suínos, observou-se que este grupo dispõe de aproximadamente 314 mil suínos, produzindo diariamente $1.515,4$ toneladas de dejetos. Verificou-se que apenas $11 \%$ das 
propriedades contam com biodigestor, e algumas ainda combinam este com a esterqueira. Isto ocorre devido a fatores como o alto custo para implantação do equipamento, a não credibilidade, por parte dos produtores, de que haverá retorno (financeiro e ambiental) e, por vezes, falta de conhecimento e explicações sobre o sistema.

As esterqueiras correspondem a $88 \%$ do total das propriedades pesquisadas, o que indica que ocorre uma degradação do ambiente, pois estes dejetos serão utilizados nas lavouras, seja na propriedade ou adjacências; pode ainda ocorrer o vazamento (pela não retirada dos dejetos ou chuvas excessivas), entre outros. As propriedades restantes, utilizam esterqueiras e lagoas de estabilização de dejetos.

Nas propriedades analisadas no município de Toledo-PR, a suinocultura é realizada em pequenas propriedades rurais, e geralmente é realizada pela família do produtor, que encontram nesta atividade uma forma de melhorar sua renda com reduzidas despesas, pois as empresas agroindustriais é que realizam o melhoramento genético, desenvolvem novas rações, fazem a entrega e coleta dos suínos.

Após a compilação das informações das propriedades, foi realizada a roteirização. Na primeira configuração, a quilometragem total mostrou-se elevada, com 15.297,53 km, num total de 156 rotas, o que implicaria, em havendo apenas um veículo, praticamente, uma rodagem de um mês para a coleta de toda a rota.

Optou-se por realizar uma divisão por setores, agregando distritos próximos, visando a melhoria das condições para a roteirização; almejando reduzir a quilometragem, alterando os custos totais finais para a coleta dos dejetos.

A nova configuração, com os três setores, resultou nas seguintes quilometragens: $4.490,40 \mathrm{~km}$ no S1 (58 rotas), $2.715,36 \mathrm{~km}$ no S2 (com 47 rotas e um produtor não roteado) e $4.921,43 \mathrm{~km}$ (com 51 rotas), perfazendo um total de $12.127,19 \mathrm{~km}$. Observa-se uma redução de $3.170,34 \mathrm{~km}$ (ou cerca de $20 \%$ ) na quilometragem anterior (primeira configuração).

Para a análise dos custos, torna-se indispensável estimar a quantidade de caminhões necessária para a coleta diária dos dejetos, pois o grande volume gerado diariamente, determina esta condição, para que seja aproveitada a totalidade do potencial energético dos dejetos. Na Tabela 5, o resumo das informações analisadas para a determinação da quantidade de caminhões.

Tabela 5 - Resumo de informações para estimativa de caminhões T13

\begin{tabular}{l|cccc}
\hline & $\begin{array}{c}\text { Número de } \\
\text { Produtores }\end{array}$ & Quilometragem & Tempo & Volume dejeto \\
\hline Setor 1 (S1) & 139 & $4.490,00$ & $112: 06 \mathrm{~h}$ & $556.186,20$ \\
Setor 2 (S2) & 111 & $2.715,36$ & $67: 36 \mathrm{~h}$ & $462.337,90$ \\
Setor 3 (S3) & 130 & $4.921,43$ & $122: 55 \mathrm{~h}$ & $496.913,10$ \\
\hline TOTAL & $\mathbf{3 8 0}$ & $\mathbf{1 2 . 1 2 7 , 1 9}$ & $\mathbf{3 0 2 : 3 7} \mathbf{~ h}$ & $\mathbf{1 . 5 1 5 . 4 3 7 , 2 0}$ \\
\hline
\end{tabular}

Fonte: Elaboração própria 
Analisando os dados de roteiro, geração de dejetos, velocidade média, entre outros, considerou-se que serão necessários 19 caminhões para a coleta diária nas 380 propriedades, operando 16 horas por dia e 25 dias no mês. O valor total para aquisição de um veículo com equipamento é de $R \$ 165.059,00$ (considerados o valor do veículo, do equipamento e do primeiro ano de seguro e licenciamento).

Conforme citado na metodologia, o cálculo dos custos do transporte foi realizado com base na metodologia utilizada por Valente; Passaglia; Novaes (2003), para os cálculos de Custos Operacionais. Englobou todas as despesas relacionadas ao veículo, ao equipamento utilizado, à manutenção, despesas com pessoal e encargos sociais, impostos, combustível, enfim, tudo que esteja relacionado ao funcionamento do veículo para coleta de dejetos.

$\mathrm{Na}$ Tabela 6, uma estimativa geral dos custos para a aquisição dos caminhões, equipamentos, instalação do centro de biodigestão, e demais valores para a análise de investimentos.

Tabela 6 - Resumo dos custos totais de investimento

Descrição $\quad$ T13

Custos (caminhão + equipamento)

$\mathrm{R} \$ 161.000,00$

Quantidade estimada de caminhões

19

Custo total investido

$\mathrm{R} \$ 3.059 .000,00$

Quantidade de motoristas

38

Custo operacional total mensal

$R \$ 410.994,32$

Despesa com compra de dejetos (pago aos $R \$ 91.956,14$ produtores)*

Investimento Biodigestor (geral)**

$R \$ 8.000 .000,00$

Manutenção mensal do biodigestor**

$R \$ 100.000,00$

Fonte Elaboração própria

* O valor da compra dos dejetos baseou-se nos valores correntes em outubro/2008, que equivale a $R \$ 25,00$ a carga de 10.300 litros.

** $\mathrm{O}$ valor do investimento e manutenção do biodigestor, foi estimado com base em valores de biodigestores de pequeno porte, considerado neste valor a compra do terreno para implantação.

Constata-se que, para o investimento total inicial, considerando os caminhões T13 e a implantação do centro de biodigestão, serão necessários $R \$ 11.059 .000,00$. A despesa mensal, que inclui o custo operacional total dos veículos, pagamento aos produtores e manutenção do biodigestor, corresponde a $\mathrm{R} \$ 602.950,46$.

Estudos apontam a geração de biogás com dejetos suínos, na proporção de $1 \mathrm{~kg}$ de dejeto para produzir $0,1064 \mathrm{~m}^{3}$ de biogás, com período de retenção de 30 dias (Lucas Junior apud SOUZA et alli 2008; NIJAGUNA, 2002). Portanto, para a geração de $1 \mathrm{~m}^{3}$ de biogás, serão necessários cerca 
de 9,40 kg de dejetos suínos, com o mesmo período de retenção. Nesta análise não foram considerados os níveis de metano, gás carbônico, configuração das rações e medicamentos utilizados na alimentação dos suínos, que influem diretamente na geração e no poder calorífico do biogás. $\mathrm{Na}$ Tabela 7 , uma estimativa de geração de biogás e equivalência de utilizações possíveis.

Tabela 7 - Estimativa de geração de biogás, energia elétrica e botijão P13

\begin{tabular}{lcccc}
\hline & kg Dejeto & $\mathbf{m 3}$ Biogás & $\begin{array}{c}\text { Energia } \\
\text { elétrica }\end{array}$ & $\begin{array}{c}\text { Botijão P13 } \\
\text { equivalente }\end{array}$ \\
\hline Geral & $1 \mathrm{~kg}$ & $0,1064 \mathrm{~m}^{3}$ & $0,532 \mathrm{kWh}$ & 0,000322 \\
$\mathrm{~T} 13(1 \mathrm{carga})$ & $10.403 \mathrm{~kg}$ & $1.106,8 \mathrm{~m}^{3}$ & $5.534,3 \mathrm{kWh}$ & 33,5 \\
\hline
\end{tabular}

Fonte Elaboração própria

Segundo informações obtidas no sítio da COMPAGÁS (2008), o valor de venda do $\mathrm{m}^{3}$ de gás natural para fins industriais é, em média ${ }^{2}, \mathrm{R} \$$ 1,19 (um real e dezenove centavos), no mês de outubro de 2008. Para a análise de rentabilidade do presente projeto, será considerado o valor de $R \$$ $1,00 / \mathrm{m}^{3}$; justificando que este biogás poderá ser utilizado pela agroindústria processadora do município, que poderia beneficiar-se ao investir em semelhante projeto.

Para a equivalência de geração de energia elétrica, cada $\mathrm{m}^{3}$ de biogás pode gerar $5,0 \mathrm{kWh}$. A companhia de energia elétrica do Estado comercializa o $\mathrm{kWh}$ de energia para a região rural do município por $\mathrm{R} \$$ 0,1622 (outubro/2008).

Com a geração de $1.515 .437,2 \mathrm{~kg}$ de dejetos ao dia, e considerados 25 dias de operação no mês, serão produzidos e coletados $37.885 .930 \mathrm{~kg}$ de dejetos, que podem gerar as quantidades de biogás e energia elétrica da Tabela 8.

Tabela 8 - Potencial de geração de biogás e energia elétrica com a coleta proposta no município de Toledo-PR

\begin{tabular}{lcc}
\multicolumn{1}{c}{ Dejetos } & Biogás & Energia elétrica \\
\hline $1 \mathrm{~kg}$ & $0,1064 \mathrm{~m}^{3}$ & $0,532 \mathrm{kWh}$ \\
$37.885 .930 \mathrm{~kg}$ & $4.031 .062,95 \mathrm{~m}^{3}$ & $20.155 .314,75 \mathrm{kWh}$ \\
\hline
\end{tabular}

\section{Fonte Elaboração própria}

Para exclusiva finalidade de análise de investimentos, considera-se que serão comercializados $40 \%$ do biogás produzido na forma de energia térmica, vendido a $R \$ 1,00 / \mathrm{m}^{3}$. Estima-se este percentual por presumir que a agroindústria local utilizaria este volume de biogás, hoje equivalente a madeira e carvão que são utilizados. O restante será transformado em

2 O valor coletado no sítio da Compagás varia de $R \$ 1,0641$ a $R \$ 1,536$, dependendo do volume consumido diariamente. 
energia elétrica, e será comercializado ao preço do kWh para a área rural, da companhia local de energia ( $\mathrm{R} \$ 0,1622 / \mathrm{kWh})$.

Após o período de retenção necessário para a geração do biogás, o dejeto deverá ser retirado e poderá ser comercializado como biofertilizante ou biocarvão. Estimou-se que, do volume inicial de dejetos, ocorra uma perda de aproximadamente $40 \%$ com líquidos e subprodutos, podendo 0 restante ser comercializado como biofertilizante $(22.731 .558 \mathrm{~kg})$, ou 2.206,9 cargas de $10.300 \mathrm{~kg}$, vendidas a $\mathrm{R} \$ 25,00$ cada carga (totalizando receitas de $R \$ 55.173,68)$. Na Tabela 9, um resumo das estimativas de receitas.

Tabela 9 - Resumo das estimativas de receitas

\begin{tabular}{lcc}
\hline Descrição & $\begin{array}{c}\text { Quantidade } \\
\text { mensal }\end{array}$ & Valor mensal \\
\hline Venda de biogás & $1.612 .425,18 \mathrm{~m}^{3}$ & $\mathrm{R} \$ 1.612 .425,18$ \\
Venda de energia elétrica & $12.093 .188,85 \mathrm{kWh}$ & $\mathrm{R} \$ 1.961 .515,23$ \\
$\begin{array}{l}\text { Venda de biofertilizante (carga de } \\
10.300 \mathrm{~kg})\end{array}$ & 2.206 & $\mathrm{R} \$ 55.173,68$ \\
\hline Total & & $\mathrm{R} \$ 3.629 .114,09$ \\
\hline
\end{tabular}

Fonte: Elaboração própria

Alguns fatores limitantes foram impostos:

- $\quad$ no primeiro ano serão apenas realizados investimentos, aprovação de projetos, licenciamentos, não havendo qualquer produção e conseqüente receita;

- $\quad$ no segundo ano de operação, no primeiro mês não haverá receita, pois, para ser produzido, o biogás precisa do tempo de retenção de 30 dias;

- $\quad$ as receitas do segundo ao quarto mês contemplam apenas a venda de biogás, considerando que, neste período, serão realizados testes e quantificações para a geração de energia elétrica;

- apenas no quinto mês do segundo ano a receita foi considerada total;

- as despesas foram consideradas totais desde o primeiro mês do segundo ano;

- foram realizados lançamentos para apenas dois anos; e

- não foi considerada a venda de créditos de carbono na análise de investimentos

Com estas informações disponíveis, realizou-se a análise de investimentos e viabilidade, e com o auxílio da planilha eletrônica Excel, constatou-se que o Valor Presente Líquido (VPL), foi de $\mathrm{R} \$ 14.422 .021,05$ ao final do segundo ano. Este índice analisa qual a relação entre $\$ 1$ hoje e $\$ 1$ no futuro, trabalhando com fluxos de caixa descontados (foi considerada uma taxa de $8 \%$ ao mês). É considerado um dos melhores métodos para analisar projetos de investimento, pois seu resultado é na moeda corrente 
da análise $(R \$)$. O critério para decisão do investimento é: se VPL $>0$, aceitase 0 investimento. Neste caso mostrou-se significativo e viável o investimento.

A Taxa Mínima de Atratividade (TMA) é o percentual que se estipula como o mínimo de retorno do projeto. Ou seja, caso o dinheiro fosse investido em outra aplicação renderia um valor percentual, o valor recebido no investimento escolhido deve ser igual ou superior a esta taxa. No Brasil, por convenção, utiliza-se a rentabilidade da caderneta de poupança, que atualmente é de $8 \%$ ao ano.

A Taxa Interna de Retorno (TIR) representa a taxa de desconto que iguala fluxos de entrada com fluxos de saída. Seu critério de decisão é: se TIR > TMA, aceita-se o projeto. No modelo T13, a TIR foi de $12 \%$ até o final do segundo ano, indicando bom retorno do investimento.

A Taxa de Rentabilidade (TR), indica quanto a empresa ganhou (\$) ao investir \$100. Não é uma medida de capital mas, da capacidade da empresa gerar lucro. Na presente análise, verificou-se que a TR $=140,80$. Ou seja, para cada $R \$ 100,00$ investidos no projeto, a empresa pode gerar $\mathrm{R} \$ 140,80$ de lucro.

O período de payback (retorno do investimento), quando todos os investimentos e despesas foram pagas e a empresa começa a ter lucros, foi de um ano e sete meses, considerado bastante salutar para a empresa.

Outra receita que pode advir com a implantação do investimento é a venda de créditos de carbono, após a elaboração e aprovação de um projeto de MDL e, com esta, poderão ser auferidos cerca de $R \$$ 1.698.965,72 por ano, considerando a redução de 149.294 toneladas de $\mathrm{CO}_{2}$ e, e o preço de venda de $\mathrm{R} \$ 11,38^{3}$ (ou US $\$ 5,00$ ) por tonelada.

Não foram considerados, na presente análise, os custos ambientais (favoráveis ou não ao projeto), bem como as externalidades negativas e/ou positivas que poderão advir com a implantação do projeto.

\section{CONCLUSÕES}

O principal objetivo do trabalho foi analisar os custos operacionais e a viabilidade para a implantação de um sistema de coleta de dejetos suínos (fase de terminação), em propriedades rurais do município de Toledo, para geração de bioenergia. Após a coleta e análise das informações, observouse que é viável a transformação de dejetos em biogás e energia elétrica, tanto para os produtores de suínos, quanto para a região em que está inserida a cidade de Toledo.

Para o estudo, foram selecionadas 380 propriedades rurais, constatando-se que apenas uma propriedade enquadra-se como média, as demais são pequenas; comprovando a asserção de que a atividade de suinocultura abrange principalmente pequenos produtores, com um regime de trabalho familiar, buscando incrementar sua renda de diversas formas.

\footnotetext{
${ }^{3}$ A cotação do dólar era de $R \$ 2,277$, no dia 18 de novembro de 2008.
} 
Nas propriedades analisadas, são engordados cerca de 314 mil suínos, que produzem diariamente 1.515,4 toneladas de dejetos (urina e esterco). Observou-se que $88 \%$ das propriedades possuem esterqueiras como destino dos dejetos, sendo utilizados como fertilizante nas lavouras da propriedade ou redondezas, com risco de contaminação do solo e dos mananciais hídricos.

Para a realização da roteirização, foram realizadas duas configurações, com o modelo de caminhão 13 toneladas, utilizando a heurística de Clark \& Wright. Para que se possa optar por este ou outro caminhão, é necessário que sejam realizadas visitas a todas as propriedades em estudo, para averiguação e descrição das barreiras físicas ou naturais, bem como o levantamento das informações das estradas a serem utilizadas. Esta pode ser uma sugestão para trabalhos futuros, podendo ser factível uma roteirização com a combinação de mais de um modelo de caminhão.

Quanto à análise de investimentos e viabilidade, constata-se que o investimento inicial, pode ser considerado elevado, no entanto observou-se que as receitas auferidas são dignas de consideração, pois o volume de dejetos coletado diariamente e o potencial de geração de biogás e energia elétrica são justificáveis.

Conclui-se, portanto, que é viável a elaboração e a implementação de projeto desta natureza na região analisada. Existe matéria-prima (dejetos) em grande quantidade, são conhecidas as formas e as metodologias para a elaboração de projetos de Mecanismos de Desenvolvimento Limpo (MDL) e de biodigestão, bem como a geração de energia térmica ou elétrica com o biogás produzido.

Outro aspecto positivo é a possibilidade de uma nova fonte de renda para o produtor rural, com a venda do dejeto suíno para a geração de bioenergia. A retirada destes dejetos das propriedades melhora o quesito ambiental destas e das propriedades adjacentes, minimizando a poluição e a degradação dos mananciais hídricos, além de propiciar ao produtor a possibilidade de ampliação do plantel.

Espera-se, com o presente trabalho, instigar pesquisadores a desenvolverem novas pesquisas relacionadas ao tema (suinocultura, utilização de dejetos, custos de transportes), para que os danos ambientais sejam controlados/monitorados; agregando valor a um resíduo que geralmente é desperdiçado, resultando em novas fontes de renda e energia aos produtores rurais, tornando mais adequada a qualidade de vida, tanto dos residentes no campo quanto na cidade.

\section{REFERÊNCIAS}

ASSOCIAÇÃO BRASILEIRA DA INDÚSTRIA PRODUTORA E EXPORTADORA DE CARNE SUÍNA (ABIPECS). Disponível em: 
$<$ http://www.abipecs.org.br/pt

/estatisticas/mundial/producao-2.html>.

Acesso em: 30/10/2009.

ABIPECS - Associação Brasileira Indústria Produtora e Exportadora de Carne Suína. Disponível em: <http://www.abipecs.org.br/estatistica> . Acesso em: jul. 2007.

ABCS - Associação Brasileira de Criadores de Suínos. Disponível em: $<$ http://www.

abcs.org.br/portal/index2.jsp>. Acesso em: jul. 2007.

BERTAGLIA, P. R. Logística e gerenciamento da cadeia de abastecimento. São Paulo: Saraiva, 2003. 509 p.

CHING, H. Y. Gestão de estoques na cadeia de logística integrada: supply chain. 3. ed. São Paulo: Atlas, 2007. 220 p.

CUNHA, C. B. Aspectos práticos da aplicação de modelos de roteirização de veículos a problemas reais. Transportes, v. 8 , n. 2, p. 5174, $2000 . \quad$ Disponível em: $<$ www.ptr.poli.usp.br/ptr/docentes/cbcunha/files/roteirizacao_aspectos_pratic os_CBC.pdf>. Acesso em: mar. 2008.

CUNHA, C. B. da; BONASSER, U. de O.; ABRAHÃO, F. T. M. Experimentos computacionais com heurísticas de melhorias para o problema do caixeiro viajante. Anais... XVI Congresso da Anpet - Associação Nacional de Pesquisa e Ensino em Transportes. Natal, outubro, 2002. Disponível em: $<$ http://www.ptr.poli.usp.br/ptr/

docentes/cbcunha/files/2-opt_TSP_Anpet_2002_CBC.pdf> . Acesso em: mar. 2008.

EMBRAPA Suínos e Aves - Empresa Brasileira de Pesquisas Agropecuárias. Suínos e Aves. Disponível em: $<$ http://sistemasdeproducao.cnptia.embrapa.br/

FontesHTML/Suinos/ SPSuinos/index.html >. Acesso em: 3 ago. 2007.

EMBRAPA - Empresa Brasileira de Pesquisas Agropecuárias. Cenários do ambiente de atuação das organizações públicas de pesquisa, desenvolvimento e inovação para o agronegócio brasileiro: 2002 2012. Brasília, 2002. Disponível em: $<$ http://www.institutoinovacao.com.br/downloads/inovacao_agronegocios.pdf >. Acesso em: 10 fev. 2008.

GOMES, M. F. M.; GIROTTO, A. F.; TALAMINI, D. J. D.; LIMA, G. J. M. M. de; MORES, N.; TRAMONTINI, P. Análise prospectiva do complexo agroindustrial de suínos no Brasil. Concórdia: EMBRAPA-CNPSA, 1992. (Documentos, 26). $108 \mathrm{p}$. 
IAP - Instituto Ambiental do Paraná. Escritório Regional Toledo. Visitas à entidade e consultas à documentos. 2008.

IBGE - Instituto Brasileiro de Geografia e Estatística. Disponível em: $<$ http://ibge.

gov.br>. Acesso em: fev. 2008.

IPARDES - Instituto Paranaense de Desenvolvimento Econômico e Social; IBPQ - Instituto Brasileiro da Qualidade e Produtividade no Paraná; GEPAI/UFSCAR - Grupo de Estudos de Políticas Agroindustriais. Análise da competitividade da cadeia agroindustrial da carne suína no Estado do Paraná. Curitiba: IPARDES, 2002. 239 p.

LOURENÇO, G. M. Agronegócio no Paraná: oportunidades e ameaças. In: CUNHA, M. S. da; SHIKIDA, P. F. A.; ROCHA Junior, W. F. da. Agronegócio paranaense: potencialidades e desafios. Cascavel: Edunioeste, 2002. p. 11-32.

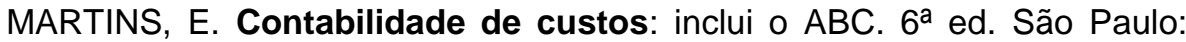
Atlas, 1998. $385 \mathrm{p}$.

MORETTO, A. C.; RODRIGUES, R. L.; PARRÉ, J. L. Tendências do agronegócio no Paraná: 1980 a 1995. IN: CUNHA, M. S. da; SHIKIDA, P. F. A.; ROCHA Junior, W. F. da. Agronegócio paranaense: potencialidades e desafios. Cascavel: Edunioeste, 2002. p. 33-56.

NIJAGUNA, B. T. Biogas technology. New Delhi: New Age International. 2002. Reprint 2006. 287 p.

NOVAES, A. G. Logística e gerenciamento da cadeia de distribuição: estratégia, operação e avaliação. 3. ed. Rio de Janeiro: Elsevier, 2007. 400 p.

OLIVEIRA, P. A. V. de. (Coord.). Manual de manejo e utilização dos dejetos de suínos. Concórdia: EMBRAPA-CNPSA, 1993. 188 p. (EMBRAPA-CNPSA. Documentos, 27).

PEREIRA, S. M. Estudo dos custos operacionais e da viabilidade de implantação de um sistema de coleta de dejetos suínos para geração de bioenergia, no município de Toledo-PR. 2009. 109 f. Dissertação (Mestrado). Programa de Pós-graduação stricito senso em Desenvolvimento Regional e Agronegócio Unioeste Campus de Toledo, Toledo.

PREFEITURA DO MUNICÍPIO DE TOLEDO. Disponível em: $<$ http://www.toledo.pr. gov.br/RAA_Minuta_12_03_07.pdf>. Acesso em: jun. 2007 
SEAB - Secretaria da Agricultura e do Abastecimento. DERAL Departamento de Economia Rural. Análise da conjuntura agropecuária safra 2007/08: suinocultura. Elaborado em setembro de 2007. Disponível em: <http://www.seab.pr.gov.br/module

s/conteudo/conteudo.php? conteudo=32>. Acesso em: mar. 2008.

SEGANFREDO, M. A.; PERIN JUNIOR, V. Dejetos suínos: adubo ou poluente? Disponível em: <http://www.cnpsa.embrapa.br/down.php?tipo=artigos\&cod_artigo =210>. Acesso em: mar. 2008

SOUZA, C. de F.; CAMPOS, J. A.; SANTOS, C. R. dos; BRESSAN, W. S.; MOGAMI, C. A. Produção volumétrica de metano - dejetos de suínos. Ciência e Agrotecnologia, Lavras-MG, v. 32, n. 1, p. 219-224, jan./fev. 2008.

VAlENTE, A. M.; PASSAGliA, E.; NOVAES, A. G. Gerenciamento de transporte e frotas. São Paulo: Pioneira Thomson Learning, 2003. 215 p. 